\title{
Decoding the Finite Element Method at the Prosthodontic- Periodontal Interface_-Elucidating the Biomechanical Behavior of the Periodontium: A Case Review
}

\author{
Sumit Munjal ${ }^{1}$, Seema Munjal ${ }^{2}$
}

\begin{abstract}
Background: The application of finite element method (FEM) is tried to improve our understanding of the distribution of forces in the stomatognathic system. The object to be studied is simulated in computer software to simplify the complex analysis and this approach involves pre-processing, discretization, defining the boundary conditions, loading configuration, and the output is graphically produced from the final data extractions.

Aim and objective: This study was undertaken to evaluate the physical form changes of the maxillary central incisor, i.e., the stresses induced within the tooth, periodontal ligament, and alveolar bone due to the normal occlusal force.

Case description: Finite element program NISA II DISPLAY III was used for accurate modeling of the tooth-periodontium system, threedimensionally. Abnormal stress levels may allow the clinician to estimate the tissue damage and implement therapeutic modalities at an appropriate stage.

Conclusion: With the present improvization, computer models of various types can be used increasingly for future fundamental biomechanics research in dentistry.

Clinical significance: Finite element method is scientific validation used for inspecting the mechanical aspects of biomaterials, tooth and also its supporting structural tissues, as in our study.

Keywords: Finite element method, Force application, Functional loads, Periodontium, Stress.

International Journal of Experimental Dental Science (2020): 10.5005/jp-journals-10029-1214
\end{abstract}

\section{BACKGROUND}

Our epoch is characterized by startling advances in computer technology, thereby enabling rapid calculations for numerous structural observations in various engineering fields. The strain gauges, holography, 2-dimensional (2D) and 3-dimensional (3D) photoelasticity, digital moiré interferometric investigation, and brittle coating analysis were earlier utilized for the same purpose. ${ }^{1}$ Finite element method (FEM) is numerical iteration and is one of the most widely used methods for solving the problems of mechanics of continuum. ${ }^{2}$ Initially, FEM was used widely only in aerospace engineering, but slowly due to the flexibility of the method to model any complex geometries and provide instant results, it made its presence felt in dentistry. ${ }^{3}$ The application is tried to improve our understanding of the distribution of forces in the stomatognathic system. ${ }^{4}$

The concept of occlusal generated stresses had been explored innumerable times in an attempt to discern but is not fully known to date. At the same time of moving, teeth flex under various loads. This is an important point in operative dentistry, prosthodontics, and implantology. ${ }^{5}$ Furthermore, inappropriate treatments, such as unnecessarily wide cavity preparation increase the potential of further trauma and possible fracture of remaining tooth structures. Yet again, it is due to stress and this relationship between the stresses in a tooth and its fracture potential should assist clinicians in eliminating or reducing the factors contributing to tooth fracture. ${ }^{6}$ This study was undertaken to evaluate the physical form changes in the periodontium of tooth under loads from the displacement and stress angles.
${ }^{1}$ Department of Periodontics, Institute of Dental Studies and Technologies, Modinagar, Uttar Pradesh, India

${ }^{2}$ Department of Prosthodontics, Faces $\mathrm{n}$ Braces Dental Research Centre, New Delhi, India

Corresponding Author: Sumit Munjal, Department of Periodontics, Institute of Dental Studies and Technologies, Modinagar, Uttar Pradesh, India, Phone: +91 9910259040, e-mail: ssmunjal@yahoo.co.in How to cite this article: Munjal S, Munjal S. Decoding the Finite Element Method at the Prosthodontic-Periodontal InterfaceElucidating the Biomechanical Behavior of the Periodontium: A Case Review. Int J Experiment Dent Sci 2020;9(2):73-76.

Source of support: Nil

Conflict of interest: None

\section{Finite Element Method Derivations: Recounting the Stratagem}

The object to be studied is graphically simulated in computer software to simplify the complex analysis and this approach involves the following steps: ${ }^{7}$

- Pre-processing/construction of the geometric model: The purpose of the initial phase is to represent geometry in terms of points, lines, areas, and volume.

- Conversion of a geometric model into finite element model/ discretization: It is the process of a dividing problem into several subunits termed element of finite dimensions. However, each element can adapt a specific shape (i.e., triangle, square, 
tetrahedron, etc.) with a specific internal strain function. Furthermore, the elements do not overlap but are connected only at the key points, which are termed nodes. The joining of elements at the nodes and eliminating duplicate nodes is then known as "Meshing".

- Assembly/material property data representation:The equations are developed for each element in the FEM mesh and assembled into a set of global equations.

- Defining the boundary conditions: It is desired that all the movements at the base of the model are restrained with regard to degrees of freedom. Otherwise, an element will act like a freefloating rigid body and will undergo a translatory or rotatory motion or a combination of these.

- Loading configuration: Application of external force on the structure at various points and its configuration.

- Processing: Constitutes solving the system of a linear algebraic equation. The stresses, however, are determined from the strains by Hooke's law.

- Post-processing: The output from the above data extraction is primarily in the numerical form, the nodal displacement, and element stresses. Graphic production and displays are usually more informative.

\section{Applications of Finite Element Method in Prostho-Periodontal Domain}

- The method has been used in studies to check various dental materials to know their behavior under load and stress.

- To study stress distribution on supporting structures in relation to designing fixed and removable prostheses. ${ }^{8}$

- This method as well as other related morphometric techniques such a macro-element and the boundary integral equation method (BIE) is useful for the assessment of complex shape changes. $^{9}$

- Finite element method is also useful for structures with inherent material homogeneity and potentially complicated shapes such as dental implants. ${ }^{10,11}$ The knowledge of physiological values of alveolar stresses is important for the understanding of bone remodeling in implantology.

- To evaluate the selection of crown preparation technique to best withstand the functional loading in the case of alumina porcelain veneers. ${ }^{12}$

- To find out stress distributions in adhesively cemented ceramic and resin-composite class II inlay restorations. ${ }^{13}$

- Carrying out a thorough appraisal of sliding and friction phenomena which affect the stress and strain created on the contact surfaces between teeth.

- To analyze stresses produced in the periodontal ligament under different loading conditions and with varying amounts of bone levels. ${ }^{8}$

- For analysis of stresses produced in the periodontal ligament when subjected to orthodontic forces. ${ }^{14,15}$

- For the prediction of facial soft tissue deformations resulting from bone repositioning ${ }^{16}$ in maxillofacial disciplines.

\section{Case Description}

The $2 \mathrm{D}$ axisymmetric FEM has been used in most of the previous research, ${ }^{17}$ but with significant shortcomings. Those 2D models like those of Taitahashi et al. are not expected to show real situations well. ${ }^{18}$ As the duplication is not feasible on human's typically asymmetric morphology, therefore modeling with the actual dimension must be preferred for a reliable analysis. ${ }^{19}$ Today, even the images from computed tomography (CT) or magnetic resonance imaging (MRI) are directly transformed into FE mesh. ${ }^{2}$ The present institutional study was conducted using the finite element program NISA II DISPLAY III, by virtue of which, accurate modeling of the tooth-periodontium system was performed threedimensionally. The model of maxillary central incisor was examined to find out the stresses induced within the tooth, periodontal ligament, and alveolar bone due to normal occlusal force directed in a palato-labial direction. The first-hand information required in the system, i.e., number of nodes for each element, Young's modulus, and Poisons ratio were systematically gathered.

Next, the boundary conditions were defined (Fig. 1). This manner of restraining prevented the model from any rigid body motion while the load is acting as described above. The figures from the FEM were graphically displayed, in the form of color-coded maps for quantitative interpretation. The curves and contours of the field variable were plotted and displayed. Also, deformed shapes could be displayed and superimposed on unreformed shapes. Eventually, the stress distribution was known on the tooth subjected to the above-described course of action.

\section{Results}

There were delineated uneven stress levels at different contours and locations of the maxillary incisor, and that was the upshot of our study. Force application causes an elastic deformation in the teeth, showing the maximum stress at the labial and palatal aspect of the cervical region (Fig. 2). This declaration noteworthily indicates that it is the cause for abfractions as opined by authors in similar other studies. 5,20

However, there was no stress seen in the pulp. In the periodontal ligament, maximum stress (Fig. 3) was seen at the cervical region and apex. Additionally, there was insignificant stress distribution in the alveolar bone. The findings of an experimental study by Lertchirakaran et al., ${ }^{21}$ which showed good qualitative and quantitative correspondence with strain-gauge data seem to corroborate this view. Abnormal stress levels may allow the

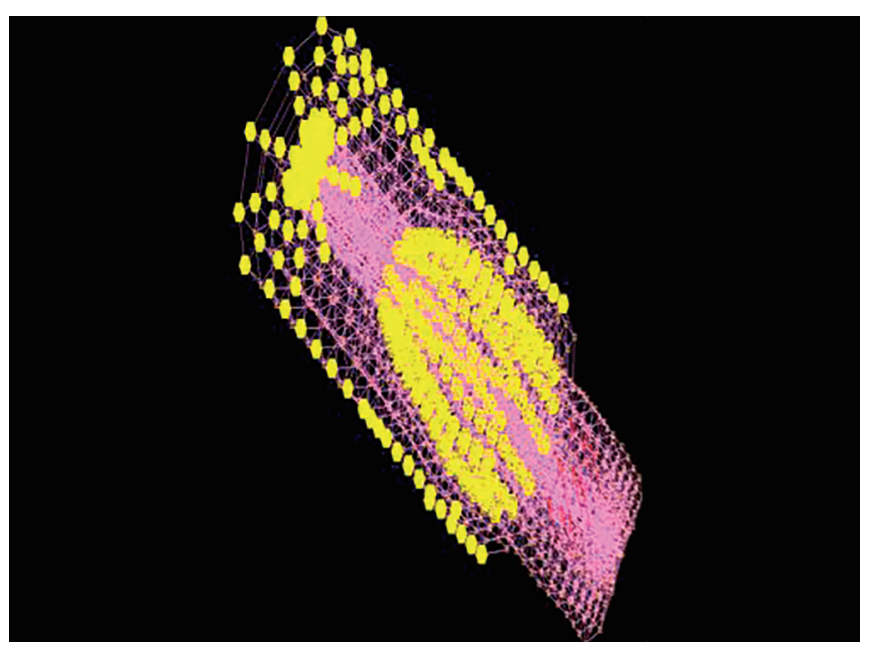

Fig. 1: Boundary conditions depicted in the model 


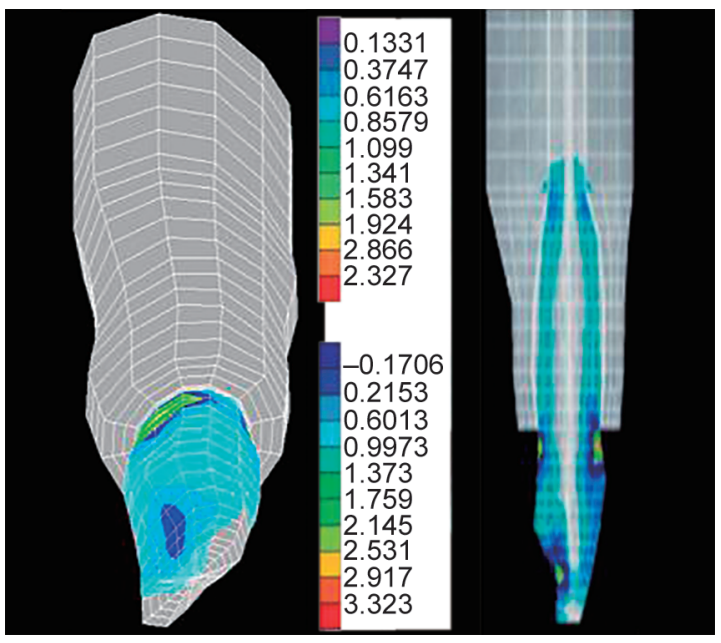

Fig. 2: The color-coding bar in the middle for calculation of stress levels and the model with a labial-palatal and palatal view

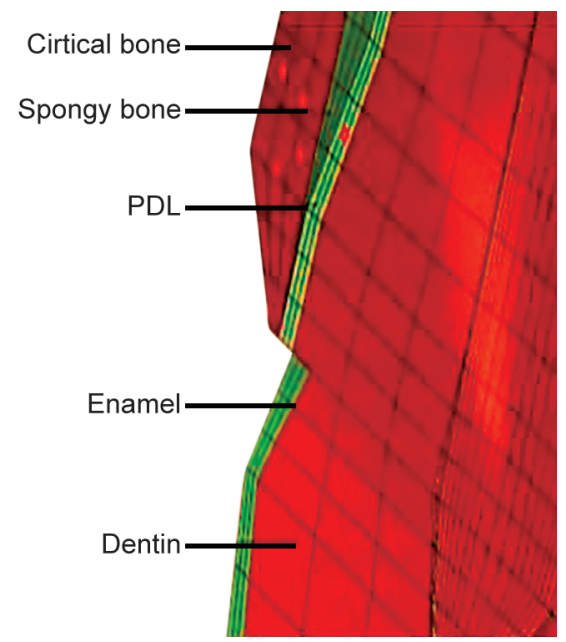

Fig. 3: Maximum stress seen in the periodontal ligament at the cervical region and apex and least in spongy and cortical alveolar bone

clinician to estimate the tissue damage and implement therapeutic modalities at an appropriate stage.

\section{Discussion}

The periodontal ligament is the most important developmental form in the evaluation of any tooth movement. Its role cannot be ignored while trying to achieve a real situation in morphometrics. Several force vectors may act simultaneously on living tissues in a $3 \mathrm{D}$ space. For this reason, it is not appropriate to analyze one plane, while ignoring the other planes because the structure is not symmetric. ${ }^{5}$ Moreover, bone, mucoperiosteum, or teeth are complex non-hemogeneous and anisotropic compositions. Occlusal overload has been proven to effectuate bone loss in relation to both endosteal implants and teeth. It must be borne in mind that bone resorption is a dynamic process primarily influenced by biological factors. Therefore, careful perusal is mandatory for any kind of survey in this zone.

The mathematical limitations inherent in morphometrics were described accurately around four decades ago by Moyers and Bookstein. ${ }^{22,23}$ This method generates a mathematical transformation related to both size and shape. The use of transformations in this manner accomplishes a greater degree of sophistication for the analysis of craniofacial studies. ${ }^{24}$ Finite element method has overshadowed other experimentations and enhancements in software and hardware have a significant positive impact on this trend. ${ }^{2}$ The model presented in the present study is as similar as possible to the real situation described in earlier attempts. ${ }^{9,12,18,21}$ Any type of stress (tensile, compressive, or shearing), when sufficient in magnitude, can inflict damage on tooth structure. ${ }^{25}$ The deformations due to occlusal loads were noted as an important factor. Furthermore, it is known that the enamel has a far greater compressive strength than tensile strength. ${ }^{26}$ Zarone et al. localized the critical sites in maxillary central restored by means of alumina porcelain veneers. ${ }^{12}$ They concluded that the chamfer with palatal overlap design serves better under a functional loading than the window technique for a crown preparation.

\section{Limitations}

The FEM has been widely used otherwise, however, the main dilemma in its application to the health sciences is to which extent is the numerical model equivalent to the real biological system. No quantitative guidelines exist to assist clinicians in making a proper adjustment to stress distributions. That is, certain approximations and assumptions are needed where multiple variables exist. The resultant value inferred from our study should be interpreted only as a reference to aid in clinical judgment. In complicated geometries, it is not accurate and conclusive, thus it must be supported with a clinical background of researches.

Close monitoring on the software showed the maximum of it at the labial and palatal aspect of the cervical region in our study (Fig. 2), which is a chronicle to that of Lee and Eakle's landmark study, ${ }^{27}$ which shed light on tooth erosions resulting from stresses. More so, even the abrasion lesions may share a similar morphologic feature. ${ }^{27}$ A stereomicroscopic study Braem et al., ${ }^{28}$ on the other hand, clearly demonstrated evidence of hydroxyapatite crystal disruptions as the cause. From the prostho-periodontal perspective, Xhonga suggested a relationship between bruxism and dental erosion. ${ }^{29}$ In a group presenting wedge-shaped cervical lesions, around $97 \%$ of the population considered had parafunctional disorders. ${ }^{30}$ The finite element studies ${ }^{6,31}$ have shown higher strains adjacent to the cementoenamel junction, which is in complete agreement with the findings of the present study. Nonetheless, a significant trend regarding advancements and optimizations of FE models ${ }^{2}$ have been described in the literature.

\section{Conclusion}

Finite element method is a valuable tool for elucidating the biomechanical behavior of the periodontium.

\section{Clinical significance}

Finite element method is scientific enough for inspecting the mechanical aspects of biomaterials, tooth and also its supporting structural tissues, as in this study. The above can hardly be measured in vivo to enable validation of the clinical assumptions.

\section{References}

1. Srirekha A, Bashetty K. Infinite to finite: an overview of finite element analysis. Indian J Dent Res 2010;21(3):425-432. DOI: 10.4103/09709290.70813. 
2. Grbović A, Mihajlović $D$. Practical aspects of finite element method applications in dentistry. Balk J Dent Med 2017;21(2):69-77. DOI: 10.1515/bjdm-2017-0011.

3. Thresher RW, Saito GE. The stress analysis of human teeth. J Biomech 1973;6(5):443-449. DOI: 10.1016/0021-9290(73)90003-1.

4. Chopade SR, Madhav VV, Palaskar J. Finite element analysis: new dimension in prosthodontic research. J Dent Allied Sci 2014;3(2):8588. DOI: 10.4103/2277-4696.159089.

5. Geramy A, Shrafoddin F. Abfraction:3D analysis by means of the finite element method. Quintessence Int 2003;34(7):526-533.

6. Khera SC, Goel VK, Chen RCS, et al. A three-dimensional finite element mode. Oper Dent 1988;13:128-137.

7. Mehta F, Joshi H. Finite element method. an overview. J Dent Med Sci 2016;15(1):38-41. DOI: 10.5455/jrmds.2016418.

8. Wakabayashi N, Ona M, Suzuki T, et al. Nonlinear finite element analyses: advances and challenges in dental applications. J Dent 2008;36(7):463-471. DOI: 10.1016/j.jdent.2008.03.010.

9. Toms SR, Eberhardt AW. A nonlinear finite element analysis of the periodontal ligament under orthodontic tooth loading. Am J Orthod Dentofacial Orthop 2003;123(6):657-665. DOI: 10.1016/S08895406(03)00164-1.

10. Williams KR, Edmundson JT. Orthodontic tooth movement analysed by the finite element method. Biomaterials 1984;5(6):347-351. DOI: 10.1016/0142-9612(84)90033-4.

11. Cattaneo PM, Dalstra M, Melsen B. The finite element method: a tool to study orthodontic tooth movement. J Dent Res 2005;84(5):428433. DOI: $10.1177 / 154405910508400506$.

12. Zarone F, Apicella $D$, Sorrentino $R$, et al. Influence of tooth preparation design on the stress distribution in maxillary central incisors restored by means of alumina porcelain veneers: a 3D-finite element analysis. Dent Mater 2005;21(12):1178-1188. DOI: 10.1016/j.dental.2005.02.014.

13. Ausiello P, Rengo S, Davidson CL, et al. Stress distributions in adhesively cemented ceramic and resin-composite class II inlay restorations: a 3D FEA study. Dent Mater 2004;20(9):862-872. DOI: 10.1016/j.dental.2004.05.001.

14. Gallas MM, Abeleira MT, Fernández JR, et al. Three-dimensional numerical simulation of dental implants as orthodontic anchorage. Eur J Orthod 2005;27(1):12-16. DOI: 10.1093/ejo/cjh066.

15. Jiang $L$, Kong $L$, Li T, et al. Optimal selections of orthodontic miniimplant diameter and length by Biomechanical consideration: a three-dimensional finite element analysis. Adv Engineer Soft 2009;40(11):1124-1130. DOI: 10.1016/j.advengsoft.2009.05.008.

16. Anitua E, Tapia R, Luzuriaga $F$, et al. Influence of implant length, diameter and geometry on stress distribution: a finite element analysis. Int J Periodont Restorat Dent 2010;30:89-95.
17. Farah W, Craig RG, Merouch RG. Finite element analysis of mandibular model. J Oral Rehab 1988;15(6):615-624. DOI: 10.1111/j.13652842.1988.tb00199.x.

18. Taitahashi N, Kitagami T, Komori T. Behavior of tooth under various loading conditions with finite element method. J Oral Rehabil 1980;7(6):453-461. DOI: 10.1111/j.1365-2842.1980.tb00464.x.

19. Rubin C, Krishnamurthy N, Capilouto E, et al. Stress analysis of the human tooth using a three dimensional finite element method. J Dent Res 1983;62(2):82. DOI: 10.1177/00220345830620021701.

20. Grippo JO. Abfraction: a new classification of hard tissue lesions of the teeth. J Esth Dent 1991;3(1):14-19. DOI: 10.1111/j.1708-8240.1991. tb00799.x.

21. Lertchirakaran V, Palamara JEA, Messer HH. Finite element analysis and strain gauge studies of vertical root fracture. J Endod 2003;29(8):529-534. DOI: 10.1097/00004770-20030800000009.

22. Moyers RE, Bookstein FL. The inappropriateness of conventional cephalometrics. Am J Orthod 1979;75(6):599-617. DOI: 10.1016/00029416(79)90093-9.

23. Bookstein FL. Foundations of morphometrics. Ann Rev Ecol Syst 1982;13(1):451-470. DOI: 10.1146/annurev.es.13.110182.002315.

24. Tanne K, Miyasaka J, Yamagata Y, et al. Three dimensional model of the human craniofacial skeleton: method and preliminary results using finite element analysis. J Biomechl Eng 1988;10(3):246-252. DOI: 10.1016/0141-5425(88)90006-4.

25. Lee WC. Readers, round table. J Prosthet Dent 1985;53(4):600. DOI: 10.1016/0022-3913(85)90664-X.

26. Bowen RL, Rodrigues MS. Tensile strength and modulus of elasticity of tooth structure and several restorative materials. J Am Dent Assoc 1962;64(3):378-387. DOI: 10.14219/jada.archive.1962.0090.

27. Lee WC, Eakle WS. Possible role of tensile stress in the etiology of cervical erosive lesions of teeth. J Prosthet Dent 1984;52(3):374-380. DOI: 10.1016/0022-3913(84)90448-7.

28. Braem M, Lambrechts $P$, Vanherle G. Stress-induced cervical lesions. J Prosthet Dent 1992;67(5):718-722. DOI: 10.1016/0022-3913(92)90178D.

29. Xhonga FA. Bruxism and its effect on the teeth. J Oral Rehabil 1977 4(1):65-76. DOI: 10.1111/j.1365-2842.1977.tb00967.x.

30. Telles D, Pegoraro LF, Pereira JC. Prevalence of noncarious cervical lesions and their relation to occlusal aspects: a clinical study. J Esthet Dent 2000;12(1):10-15. DOI: 10.1111/j.1708-8240.2000. tb00193.x.

31. Kaewsuriyathumrong C, Soma K. Stress of tooth and PDL structure created by bite force. Bull Tokyo Med Dent Univ 1993;40: 217-232. 